\title{
CUATRO POEMAS INÉDITOS ENTRE LA CORRESPONDENCIA DE SALVADOR NOVO
}

\author{
JUAN GONZÁLEZ MORFÍN \\ Universidad Panamericana, Ciudad de México
}

\begin{abstract}
Resumen: En este trabajo, se presentan cuatro poemas enviados a Salvador Novo por un joven poeta nayarita así como una carta que los acompañaba. De esta, se desprende que, aun sin conocer personalmente al autor, Novo se había venido convirtiendo en su tutor intelectual y guía de confianza. Los poemas tienen cierta calidad literaria, lo que permite pensar que fueron conservados no solamente por razones sentimentales, sino también por su contenido artístico. La presentación de estos, además de acercarnos a una faceta menos conocida de Novo, abre la posibilidad de rastrear la ulterior producción poética del que los envió, pero también invita a aprovechar más el enorme material existente en archivos con la correspondencia privada de este y otros autores.
\end{abstract}

Palabras clave: poemas, correspondencia, archivos, intelectuales, modernismo.

Abstract: In this work, four poems sent to Salvador Novo by a young poet from Nayarit are presented as well as a letter that accompanied them. From this, it follows that, even without knowing the author personally, Novo had become his intellectual tutor and trusted guide. The poems have a certain literary quality, which suggests that they were preserved not only for sentimental reasons, but also for their artistic content. The presentation of these, in addition to approaching a less known facet of Novo, opens the possibility of tracing the subsequent poetic production of the young artist who sent them, but also invites us to take more advantage of the enormous material existing in archives with the private correspondence of this and other authors.

Keywords: Poems, Correspondence, Archives, Intellectuals, Modernism.

\section{Presentación del documento}

Del grupo de escritores conocidos como contemporáneos $^{1}$, sin duda uno de los más versátiles fue Salvador Novo en sus facetas de poeta, crítico literario, editorialista, autor dramático, cronista y, según se verá en este breve estudio, tutor y guía de poetas emergentes ${ }^{2}$.

${ }^{1}$ Un estudio útil para acercarse tanto a esta generación de intelectuales se encuentra en Sheridan (1985).

2 Salvador Novo (1904-1974), fue uno de los poetas mexicanos más destacados de la primera mitad del siglo XX. Desde muy joven se abrió paso en el mundo de la cultura en buena parte por su cercanía a los hombres del poder, como el secretario de educación 
Cuatro poemas inéditos entre la correspondencia de Salvador Novo

La correspondencia privada de cualquier personaje suele aportar datos valiosos sobre aspectos muchas veces poco conocidos de su personalidad, así como otros pormenores que terminan de completar el cuadro biográfico: asuntos personales, amigos, relaciones con las empresas editoriales o el gobierno, etc.

En el fondo Salvador López Antuñano del archivo del Centro de Estudios de Historia de México, se encuentra abundante material epistolar dirigido a Salvador Novo. Cada legajo con una gran variedad de temas y corresponsales. Por ejemplo, en el que será objeto de nuestro estudio, junto con los documentos que se presentarán a continuación, se hallan cartas y tarjetones de Alfonso Reyes, Andrés Soler, Agustín Salvat y otros menos conocidos. En total, 15 cartas mecanografiadas, 11 copias al carbón de cartas mecanografiadas y 5 tarjetas manuscritas. De ellas, una enviada por Alfonso Reyes, al parecer juntamente con un libro, en la que está escrito el siguiente mensaje: "¡Pero, querido Salvador! Mi librito Parentalia no salió mezclado de buena y mala compañía ${ }^{3}$, Asómese a él en ratos perdidos. A lo mejor le gusta y descubre en él un tono de voz que no esperaba encontrar en mî" (Reyes, 1959). Si bien ya el lenguaje críptico de esta breve nota de presentación podría servir para escribir un artículo buscando desentrañarla, sin embargo, hemos optado por desempolvar mejor otros documentos de los que se encuentran en esta carpeta que pudieran ser interesantes y dar vida a un poeta hasta este momento desconocido.

En efecto, entre la variada correspondencia dirigida a Novo de este legajo, existen algunos poemas que, en un primer momento, podía pensarse fueran suyos; sin embargo, una carta los antecede a modo de presentación que explica su existencia en esa carpeta.

El autor era un estudiante nayarita radicado para sus estudios en Guadalajara y que ya había tenido en otras ocasiones la suerte de recibir de Novo la benignidad de sus comentarios sobre el material poético que le había enviado ${ }^{4}$. Tantas veces, que temía que en esta ocasión no se tomara la misma deferencia, por lo que, si fuera así, lo disculpaba desde antes.

pública durante el régimen de Plutarco Elías Calles, el doctor José Manuel Puig Casauranc, de quien Novo fue secretario particular. Su poesía encontró eco en los ambientes internacionales, lo que le permitió, todavía muy joven, interactuar con García Lorca. Además de su original sensibilidad, la poesía de Novo tuvo una nota particular que la distinguió: el humorismo (Cuesta, 1985: 200).

${ }^{3}$ Esta obra de Reyes, escrita en honor de su madre, está firmada en mayo de 1957, pero, a la vista de esta tarjeta de presentación, no vio la luz sino más de dos años después (Reyes, 1958).

${ }^{4}$ Jorge Rodríguez Gollaz, Oriundo de Ruiz, Nayarit, pueblo minero relativamente cercano a la costa. Este último dato es relevante, porque tanto por ser una región minera, como por estar cercana a la costa, la presencia de afroamericanos y mulatos era más común que en otras regiones del país. El segundo de los poemas que envió a Novo versa sobre este punto. 
Se ve que la orientación que ahora pedía a Novo ya la había buscado en el medio en que se desenvolvía, aunque vanamente. De hecho, hubiera querido encontrar un guía, como lo había sido Novo, en el lugar donde vivía, pero no lo había conseguido, por más que sí había encontrado en Guadalajara otros jóvenes que compartían sus inquietudes literarias:

\begin{abstract}
Realmente sé que es una desfachatez mía, pero, Maestro, tengo tantas inquietudes y son tan pocos mis medios para organizarlas que por momentos siento que se asfixia todo lo que me rodea, este medio en el que me desenvuelvo, tan árido de sentimientos artísticos. Actualmente estoy estudiando en Guadalajara, aunque en este mes estoy de vacaciones en mi pueblo y en aquella ciudad mis inquietudes han tenido un desahogo porque me he encontrado con muchachos de mis mismas aspiraciones, todo lo que sea arte y en especial Literatura, y hasta he hecho Teatro experimental como actor, aconsejado por un conocido suyo y amigo mío, Alfredo Castilla de Tepic, y el maravilloso mundo del teatro ha calmado en parte esta sed de hacer algo estético (Rodríguez, 1959a).
\end{abstract}

Se queja a continuación del vacío que ha encontrado en otros reconocidos personajes del mundo literario, pues no lo han tomado en cuenta, como anteriormente lo ha hecho Novo: "Aunque [en Guadalajara] existen muchos intelectuales, estos se encuentran en su torre de Marfil y son lo suficientemente egoístas como para no dar siquiera una opinión” (Rodríguez, 1959a).

Reconoce humildemente que quizá lo que escribe no sea de calidad literaria y, por lo tanto, su vocación artística no vaya en la línea de ser un escritor, pero es precisamente eso lo que desea conocer de alguien que, con autoridad, pueda indicárselo:

Sé que no estoy preparado, que me falta cultura, pero lo que quisiera saber es si en mí hay algo que pudiera dejar asomar un probable escritor, si vale la pena seguir perseverando, porque hay veces, Maestro, que la hostilidad del medio, de los compañeros, de los familiares, le hacen desesperar a uno. Quisiera que fuera Ud. la persona que me contestara lo que anteriormente menciono; quizá a Ud. le sorprenderá o le causará fastidio oír o, mejor dicho, leer mi petición, porque me imagino que ha de estar asediado por cartas parecidas, pero me haría tan feliz si me contestara, aunque su consejo fuera contrario a mí; no importa, lo estimo a Ud. tanto y lo he convertido en mi guía, que todo lo que me indicara lo seguiría con gusto (Rodríguez, 1959a). 
Además del respeto, admiración y confianza hacia Novo, el joven Rodríguez Gollaz ponía en las manos de su maestro el futuro que podía tener como poeta. La respuesta que haya recibido no la conocemos, pero sí que sus poemas y la carta de presentación que los acompañó permanecieron entre la correspondencia que Novo había de conservar.

El primer poema, formado por cinco sextetos en dodecasílabos, con reminiscencias tanto de la poesía de Gaspar Núñez Arce como de la de Francisco Pezoa Véliz ${ }^{5}$, refleja el dolor de quien comienza a buscar una respuesta a sus inquietudes religiosas no satisfechas por las vías institucionales.

El segundo está lleno de remembranzas modernistas en cuanto al lenguaje y colorido, posiblemente influenciado por los moldes de Darío, aunque con un ritmo que pudiera haber sido inspirado, igual que el tema, por el poeta cubano Nicolás Guillén. Es quizá de los cuatro el de más valor literario, por más que pudiera aparecer un poco fuera de época.

El tercero, retoma un asunto religioso para dirigirse a la Guadalupana: es quizás el más "vanguardista" y menos contaminado por el modernismo, con un cierto dejo de López Velarde.

Por último, un poema quizá escrito para descansar, sin mayores aspiraciones que expresar en verso el ejercicio sereno del poeta: versificar. Probablemente en esto no sin influencia de la producción de los años 20-30 de Novo, pero también este con resabios modernistas.

Inmediatamente después de estos, se transcribe la carta que los presenta, de la que se han ofrecido ya unos cuantos datos del artista.

\section{Poema 1: Ruega por nosotros}

Ruega por nosotros, Señor Jesucristo, ruega por nosotros, los que no hemos visto ni fama ni gloria nimbarnos de luz. Ruega por nosotros los abandonados de suerte y amores y que resignados vamos por el mundo cargando una cruz.

Ruega por nosotros, que siempre soñando vamos por el mundo, andando y andando, en el infinito buscando un ideal.

${ }^{5}$ Del primero, respira la nostalgia por un sentido religioso que se ha ido perdiendo; del segundo, el molde en dodecasílabos. 
Los que por la vida buscamos, buscamos

Señor Jesucristo y al fin terminamos

en un manicomio o en un hospital.

Ruega por nosotros, los incomprendidos los que despreciamos del mundo los ruidos y damos la gloria por una mujer.

Los que no sabemos de tibios hogares, los que no pisamos jamás tus altares, pues somos indignos hasta de creer.

Ruega por nosotros, Señor, los profanos que no oímos misa con tus besamanos que besan las cruces con labios impuros. $\mathrm{Ni}$ necesitamos para estar contigo dar falsas limosnas a falsos mendigos, ni agua bendita, sermón ni conjuros.

Ruega por nosotros, Señor, los poetas, los que te confiamos las ansias secretas en versos que llevan mensajes de amor. Los que no queremos honor ni presea y a todo decimos, Señor, así sea, si tú así lo quieres, será así Señor (Rodríguez, 1959b).

\section{Poema 2: Danza}

Va la mulata danzando, danzando de negro en negro.

Latido en ritmo de zamba, bronce de pechos morenos, manos de miel y melcocha que se enroscan en su cuerpo. La hoguera de lentejuelas que borda de plata el cielo provoca lluvia de estrellas, volcadas en pelo negro. Tambores agonizantes con su sum sum lloran duelo, 
lúgubres ecos de sombra, trinos de pájaro muerto. Fiesta de carne mulata Danza de amor y de miedo escenario de mil fieras en medio del bosque espeso.

Va la mulata danzando, danzando de negro en negro.

Lleva en su tez bronceada el compás del movimiento, abiertos grandes los ojos, inmensos como el sendero. Va la mulata danzando, danzando de negro en negro.

Manos huesudas y largas palmotean sobre el cuero, dejan escapar el ritmo que hace trepidar el cielo. Va la mulata danzando, danzando de negro en negro.

Círculo de ojos ansiosos del baile de la hembra en celo, ávidos lanzan miradas que a la mulata siguiendo le acarician las caderas y se le prenden al seno. Agónicos estertores de mil gritos plañideros de pitos de caña y flautas y tambores de los negros semejan ritmo pausado de sollozo de pandero.

Va la mulata danzando danzando de negro en negro.

Sombra del bosque en la tierra, tierra del bosque en el cielo. Perfume de flor marchita 
embalsama los senderos, danza de ritmo pausado dum dum de angustia de negros, ritmo de negros contornos, luna de negros reflejos, negros rumores del bosque, negros tambores de cuero, negra mulata de bronce, círculo negro de negros. Agitando las dos manos despeinándose el cabello, va la mulata danzando, señalando con los dedos la hojarasca del bosque, blando tapiz del silencio.

Al compás del sonsonete contorsionando su cuerpo, moviendo hacia el sur y el norte sus caderas y sus senos, va la mulata danzando, danzando de negro en negro.

Resplandores de la hoguera, entristecen el ambiente, aromas de verde incienso aromas del bosque umbroso para el ritual de los negros. Los rugidos de las fieras se levantan hacia el cielo trompetas de guerra y llanto y redobles de silencio. Va la mulata danzando, danzando de negro en negro (Rodríguez, 1959c).

\section{Poema 3: Guadalupana}

Flor dulce y morena de la montaña

-insinuación divina-

de pie entre la peña y los abrojos, como humilde niña. 
Cuatro poemas inéditos entre la correspondencia de Salvador Novo

Inmensidad tranquila

en el diálogo amoroso del indio,

para darle las rosas escondidas

sin turbar la ingenuidad de su vida.

Rosas... Milagro... En un breve instante

¡Nos dio eternidad la Suave Niña! (Rodríguez, 1959d).

\section{Poema 4: Rumor}

Rumor de las olas que inquietas se mecen rumor de las brisas que surca la mar, rumor de las crestas de espuma que crecen y contra las rocas se van a estrellar.

La blanca gaviota de grácil figura sumerge su cuerpo en el mar rugidor y emerge airosa entre la blancura

de la inquieta espuma de amargo sabor.

Rumor de sus alas que baten la brisa al ir a la playa el calor a tomar sobre la cual manso el mar se desliza volviendo incansable la arena a lavar.

Rumor de conjuntos de mar y de viento, rumor de las palmas de hermoso color, rumor de las olas que en su movimiento azotan la costa con leve rumor (Rodríguez, 1959d). 
Juan González Morfín

\section{Carta de Jorge Rodríguez Gollaz a Salvador Novo}

Jorge Rodríguez Gollaz,

Amado Nervo \# 8,

Ruiz, Nayarit.

Agosto 6 de 1959

Sr. D. Salvador Novo,

Madrid 13,

México, D.F.

Querido maestro:

Hace ya tanto tiempo que no había vuelto a distraer su atención, que hoy que lo hago temo que ya no me recuerde absolutamente y que no tenga la benignidad de otras veces para conmigo y no me llegue a contestar.

Sé bien que no debiera escribirle a usted que tiene tantas ocupaciones importantes que atender y que no puede desperdiciar su tiempo contestando cartas de muchachos como yo, que no le pueden ofrecer ningún interés intelectual, pero lo hago esta vez alentado por la suerte de mis anteriores y porque quiere de usted un consejo a mis aspiraciones literarias. Le estoy adjuntando unas cosas que he hecho.

Realmente sé que es una desfachatez mía, pero, Maestro, tengo tantas inquietudes y son tan pocos mis medios para organizarlas que por momentos siento que se asfixia todo lo que me rodea, este medio en el que me desenvuelvo, tan árido de sentimientos artísticos. Actualmente estoy estudiando en Guadalajara, aunque en este mes estoy de vacaciones en mi pueblo y en aquella ciudad mis inquietudes han tenido un desahogo porque me he encontrado con muchachos de mis mismas aspiraciones, todo lo que sea arte y en especial Literatura, y hasta he hecho Teatro experimental como actor, aconsejado por un conocido suyo y amigo mío, Alfredo Castilla de Tepic, y el maravilloso mundo del teatro ha calmado en parte esta sed de hacer algo estético; pero en cuanto a la cuestión literaria, aunque existen muchos intelectuales, estos se encuentran en su torre de Marfil y son lo suficientemente egoístas como para no dar siquiera una opinión. Yo sé que no estoy preparado, que me falta cultura, pero lo que quisiera saber es si en mí hay algo que pudiera dejar asomar un probable escritor, si vale la pena seguir perseverando, porque hay veces, Maestro, que la hostilidad del medio, de los compañeros, de los familiares, le hacen desesperar a uno. Quisiera que fuera Ud. la persona que me contestara lo que anteriormente menciono; quizá a Ud. le sorprenderá o le causará fastidio oír o, mejor dicho, leer mi petición, porque me imagino que ha de estar asediado por cartas parecidas, pero me haría tan feliz si me contestara, aunque su consejo fuera 
contrario a mí; no importa, lo estimo a Ud. tanto y lo he convertido en mi guía, que todo lo que me indicara lo seguiría con gusto.

Nuevamente le pido mil perdones por mi intromisión a sus ocupaciones. Gracias (Rodríguez, 1959a).

\section{Consideraciones finales}

Aunque de Salvador Novo existe ya algo publicado sobre su correspondencia ${ }^{6}$, es tan abundante esta que se podría escribir mucho más, tanto de lo que él enviaba como de lo que recibía. En general, es muy enriquecedor acercarse a la vida profunda de los autores a través de su correspondencia ${ }^{7}$. Los poemas recién presentados que se encuentran en aquella recibida por Novo, permiten descubrir una faceta quizá no tan conocida de Novo, como asesor de jóvenes artistas y, sobre todo, desvelan a un poeta desconocido, cuando menos a nivel nacional, del que se puede seguir la pista.

De los cuatro poemas, los numerados con el 2 y el 3 son quizá los más interesantes. El número 2, por la cadencia y recursos literarios mostrados; el tercero, por los intentos, si bien breves, de romper con los moldes establecidos para buscar incorporarse a una poesía de vanguardia. ¿Lo habrá conseguido el poeta Rodríguez Gollaz en obras sucesivas? De momento no se ha realizado una investigación a fondo que rastree su producción posterior acudiendo a quienes pudieran haberlo conocido, lo cierto es que, como en muchos otros casos, su obra literaria -si la hubo, más allá de estos poemas- permanece en el olvido.

Finalmente, una duda que persistirá es si los poemas fueron conservados por Novo en razón de una cierta calidad literaria, o por la estima que sentía hacia el poeta novel, o bien su conservación fue fruto únicamente del orden con que este conservaba toda la correspondencia que le llegaba.

\section{Referencias bibliográficas}

Cuesta, Jorge (1985). Antología de la poesía mexicana moderna. México: Fondo de Cultura Económica (Lecturas mexicanas 99).

López Velarde, Ramón (1991). Correspondencia con Eduardo J. Correa y otros escritos juveniles. México: Fondo de Cultura Económica.

\footnotetext{
${ }^{6}$ Véase Villaurrutia 1966. Por otro lado, en la Fundación Federico García Lorca, de Madrid, se conservan tres cartas de Salvador Novo a Federico García Lorca que ya han sido trabajadas y parcialmente publicadas por Valender (1996).

7 Piénsese, por ejemplo, en la de López Velarde con Eduardo J. Correa (López, 1991).
} 
Reyes, Alfonso (1958). Parentalia. México: Fondo de Cultura Económica.

Sheridan, Guillermo (1985). Los Contemporáneos ayer. México: Fondo de Cultura Económica.

Valender, James (1996). Cartas de Salvador Novo a Federico García Lorca. Cuadernos Hispanoamericanos, 548. 7-20.

Villaurrutia, Xavier (1966). Cartas de Villaurrutia a Novo (Prólogo de Salvador Novo). México: INBA.

\section{Fuentes inéditas:}

Reyes, Alfonso (1959). Tarjetón tipo esquela de Alfonso Reyes a Salvador Novo. Archivo del Centro de Estudios de Historia de México Carso (CEHM), fondo Salvador Novo, serie Salvador López Antuñano, legajo 10, carpeta 3, ff. 6-7. México.

Rodríguez, Jorge (1959a). Carta a Salvador Novo, Ruiz (Nayarit), 6 de agosto, CEHM, fondo Salvador Novo, serie Salvador López Antuñano, legajo 10, carpeta 3, f. 11. México.

Rodríguez, Jorge (1959b). CEHM, fondo Salvador Novo, serie Salvador López Antuñano, legajo 10, carpeta 3, f. 12. México.

Rodríguez, Jorge (1959c). CEHM, fondo Salvador Novo, serie Salvador López Antuñano, legajo 10, carpeta 3, f. 13. México.

Rodríguez, Jorge (1959d). CEHM, fondo Salvador Novo, serie Salvador López Antuñano, legajo 10, carpeta 3, f. 14. México. 